\title{
Synaptic Dynamics Do Not Determine Proper Phase of Activity in a Central Pattern Generator
}

\author{
Pascale Rabbah ${ }^{1}$ and Farzan Nadim ${ }^{1,2}$ \\ ${ }^{1}$ Department of Biological Sciences, Rutgers University, and ${ }^{2}$ Department of Mathematical Sciences, New Jersey Institute of Technology, Newark, New \\ Jersey 07102
}

\begin{abstract}
Rhythmic motor activity often requires neuronal output to the muscles to arrive in a particular sequence. At the pattern-generator level, this requires distinct activity phases in different groups of constituent neurons. The phase differences between rhythmically active neurons in a network are thought to arise from the interplay between their intrinsic properties and the temporal dynamics of synapses among these neurons. In the rhythmically active pyloric network of the lobster Panulirus interruptus, synaptic connections from the pacemaker ensemble to the follower neurons [lateral pyloric (LP) and pyloric constrictor (PY)] are thought to be primarily responsible for the proper phase of activity (pacemaker-LP-PY) across all frequencies $(0.5-2 \mathrm{~Hz})$ of the pyloric rhythm. We test this hypothesis by characterizing the synapses from the pacemaker ensemble to the LP and PY neurons. Paired comparisons show that these two synapses are not significantly different in strength or in the extent of short-term depression. To examine the level to which intrinsic properties of the follower neurons determine their relative activity phase, we block all chemical synapses within the network and drive the LP and PY neurons rhythmically using artificial synaptic currents with identical strength and dynamics implemented with the dynamic-clamp technique. In response to these identical synaptic inputs, the LP and PY neurons maintain the proper relative phase of activity. These results strongly indicate that the relative phase of activity among these follower neurons within the pyloric network is not dictated by their synaptic inputs but is solely determined by their distinct intrinsic properties.
\end{abstract}

Key words: synaptic plasticity; synaptic depression; motor system; dynamic clamp; stomatogastric; pyloric rhythm

\section{Introduction}

Oscillatory activity is found at all levels in the nervous system, from cognitive functions (Singer, 1993; Klimesch, 1999) to sensory systems (Laurent et al., 1996; Stopfer et al., 1997; Pareti and De Palma, 2004) and motor activity (Von Euler, 1983; Marder, 2000; MacKay-Lyons, 2002). The neural networks underlying these oscillatory activities usually operate over a wide frequency range (Marder and Calabrese, 1996), whereas, in each cycle, the relative temporal activity (phase) of individual elements within the network remains mostly invariant (O'Keefe and Recce, 1993; Dicaprio et al., 1997; Hooper, 1997a,b). In many cases, this relative phase coding ensures appropriate functional rhythmic patterns of neural networks (Hooper, 1997a).

We explore mechanisms responsible for setting relative activity phases using the rhythmically active pyloric motor network (frequency, 0.5-2 Hz) of the spiny lobster, Panulirus interruptus. In this network, the coactive anterior burster $(\mathrm{AB})$ and two pyloric dilator $(\mathrm{PD})$ neurons comprise the pacemaker ensemble responsible for the generation of the pyloric rhythm. The pace-

Received Aug. 4, 2005; revised 0ct. 12, 2005; accepted 0ct. 24, 2005.

This work was supported by National Institutes of Health Grant MH-60605 (F.N.). We thank Jorge Golowasch, Nickolas Kintos, and Isabel Soffer for their helpful comments and discussions.

Correspondence should be addressed to Farzan Nadim, Department of Biological Sciences, Rutgers University, 101 Warren Street, Newark, NJ 07102. E-mail: farzan@njit.edu.

DOI:10.1523/JNEUROSCI.3284-05.2005

Copyright $\odot 2005$ Society for Neuroscience $\quad$ 0270-6474/05/2511269-10\$15.00/0 maker ensemble produces inhibitory chemical postsynaptic potentials in the remaining follower neurons. The pyloric rhythm is a relatively stereotyped triphasic pattern of activity consisting of bursts of action potentials in the $\mathrm{AB} / \mathrm{PD}$ ensemble (phase 1), followed by the lateral pyloric (LP) (phase 2) and the pyloric constrictor (PY) (phase 3) neurons. The two classes of follower neurons LP and PY maintain their relative activity pattern, in which the LP neuron leads the PY neuron in each cycle, over a wide frequency range of the rhythm (Miller and Selverston, 1982b; Hooper, 1997a). The relative phases of the LP and PY neurons in each cycle have been attributed to their distinct intrinsic properties (Hartline and Gassie, 1979; Tierney and HarrisWarrick, 1992; Harris-Warrick et al., 1995a,b) as well as the strength and time course of the synaptic inputs these follower neurons receive from the pacemaker ensemble (Eisen and Marder, 1984; Mamiya and Nadim, 2004).

We investigate the extent to which the relative activity phases of the follower LP and PY neurons are determined by the dynamics of the synaptic inputs they receive from the pacemaker ensemble. We first characterize the dynamics of these synapses (strength, time course of release, extent and time constant of depression, dependence on cycle frequency, and duty cycle) by manipulating both PD neurons in voltage clamp using various injection stimuli and recording simultaneously from the follower neurons. To examine the contribution of intrinsic properties to the relative phases of activity, we block the synapses from the 
pacemaker ensemble to the follower neurons and replace these inherent synapses with identical artificial synapses. These experiments demonstrate the influence of synaptic inputs versus intrinsic properties in determining the proper relative phase of activity in this rhythmic network.

\section{Materials and Methods}

Preparation and identification of the neurons. Experiments were conducted on adult male spiny lobsters ( $P$. interruptus) purchased from Don Tomlinson Fisheries (San Diego, CA). The animals were maintained in artificial seawater tanks at $12-15^{\circ} \mathrm{C}$ until use and were anesthetized by cooling on ice for $30 \mathrm{~min}$ before each dissection. The stomatogastric nervous system (STNS) [including the stomatogastric (STG), esophageal, and the commissural ganglia] was removed using standard methods (Selverston et al., 1976; Harris-Warrick et al., 1992) and pinned down in a Sylgard-coated Petri dish. The STG was desheathed to allow penetration of the cell bodies and effective superfusion of the neurons using normal saline at $18^{\circ} \mathrm{C}, \mathrm{pH} 7.35$, containing the following (in mM): 12.8 $\mathrm{KCl}, 479 \mathrm{NaCl}, 13.7 \mathrm{CaCl}_{2}, 10.0 \mathrm{MgSO}_{4}, 3.9 \mathrm{NaSO}_{4}, 11.2$ Trizma base, and 5.1 maleic acid.

Microelectrodes for neuron impalement were pulled using a FlamingBrown micropipette puller (P87; Sutter Instruments, Novato, CA) and filled with $0.6 \mathrm{M} \mathrm{K}_{2} \mathrm{SO}_{4}$ plus $0.02 \mathrm{M} \mathrm{KCl}$ (resistances of 8-13 M $\Omega$ ). Neuron identification was accomplished by matching intracellular action potential recordings to their corresponding extracellular recordings on motor nerves (Selverston et al., 1976; Harris-Warrick et al., 1992). Intracellular recordings were made from the soma of the neurons using Axoclamp 2B amplifiers (Molecular Devices, Sunnyvale, CA), and extracellular recordings were amplified using a differential AC amplifier model 1700 (A-M Systems, Carlsborg, WA).

Comparison of the synaptic dynamics from the pacemaker ensemble to $L P$ and PY neurons. The $\mathrm{AB}$ and $\mathrm{PD}$ neurons (known as the pyloric pacemaker ensemble) make anatomically identical inhibitory chemical synaptic connections to all other (follower) pyloric network neurons [with the exception of the $\mathrm{AB}$ to ventricular dilator (VD) synapse] (see Fig. $1 B$ ) (Eisen and Marder, 1982). However, the temporal dynamics of the synapses from the $\mathrm{AB}$ neuron alone have been shown to be different from the dynamics of the synapses efferent from the PD neurons (Eisen and Marder, 1982; Rabbah et al., 2002). During the normal ongoing pyloric rhythm, the $\mathrm{AB}$ and $\mathrm{PD}$ neurons oscillate in synchrony because of their strong electrical coupling, thus the follower neurons experience a compound IPSP from both AB and PD neurons. In this manuscript, we do not attempt to characterize the synaptic dynamics of the $A B$ and $P D$ neurons separately; instead, we treat $\mathrm{AB} / \mathrm{PD}$ as a single functional unit. In particular, we use voltage-clamp stimulations of the two PD neurons to elicit synaptic release from both $\mathrm{AB}$ and $\mathrm{PD}$ neurons and record the compound IPSPs from the LP and PY neurons. We performed a series of control experiments that allowed us to conclude that the $A B$ synapses onto the LP and PY neurons can be recruited through the PD neurons alone, without the need to impale the $\mathrm{AB}$ neuron soma ( $n=7$; data not shown) (Rabbah et al., 2002). First, we stimulated the PD neurons in voltage clamp in control saline and recorded the compound $\mathrm{AB} / \mathrm{PD}$ IPSPs (IPSP $\mathrm{AB}_{\mathrm{ADD}}$ ) in the follower neurons. We then stimulated the PD neurons while the preparation was superfused with $5 \mu \mathrm{M}$ picrotoxin (PTX), which blocks the glutamatergic synaptic release from the AB neuron (Marder and Paupardin-Tritsch, 1978). Thus, the IPSPs recorded in the follower neurons were those elicited solely by the PD neurons $\left(\mathrm{IPSP}_{\mathrm{PD}}\right.$ ). Because there are no drugs that effectively block gap junctions in the STG, to isolate the component of the chemical synapse that was elicited by the $\mathrm{AB}$ neuron (IPSP $\mathrm{AB}_{\mathrm{B}}$ ), IPSP $\mathrm{PD}_{\mathrm{PD}}$ elicited in PTX conditions were digitally subtracted from the IPSP $\mathrm{PB}_{\mathrm{AB} / \mathrm{PD}}$ elicited in control conditions. In separate experiments, we stimulated the PD neurons while the preparation was superfused with $1 \mathrm{~mm}$ tetraethylammonium (TEA) to block the cholinergic PD synapses (Marder and Eisen, 1984) and recorded IPSP $\mathrm{AB}_{\mathrm{AB}}$ from the follower neurons. The strength and dynamics of IPSP ${ }_{\mathrm{AB}}$ obtained when using TEA were not quantitatively significantly different from those obtained when the PTX traces were subtracted from the control traces.
The inhibitory synapses between the pacemaker ensemble and the LP and PY neurons use voltage-dependent (graded) release of neurotransmitter as the major form of transmission (Maynard and Walton, 1975; Graubard, 1978; Graubard et al., 1980; Johnson and Harris-Warrick, 1990; Johnson et al., 1995). To isolate this form of synaptic release, spikemediated transmission was blocked by superfusing the preparation with Panulirus saline containing $10^{-7}$ M TTX (Biotium, Hayward, CA). TTX blocks spontaneous rhythmic activity, which allowed for better control of the membrane potential of the neurons. TTX also removes modulatory inputs from anterior ganglia that might otherwise affect the dynamics of the IPSPs recorded (Raper, 1979). Because any input that alters the membrane potential of a neuron can conceivably alter the amount of neurotransmitter released by that neuron, these sets of experiments were performed in voltage clamp.

One PD neuron was voltage clamped with two electrodes to a holding membrane potential $\left(V_{\text {hold }}\right)$ of $-60 \mathrm{mV}$. Because of the technical restriction of placing two electrodes in each PD neuron, as well as placing a recording electrode in the LP and PY neurons, the second PD neuron was impaled with only one electrode. Low-resistance electrodes were used in both PD neurons for stimulation. The current that was used to voltage clamp the first PD neuron was scaled up (using the specification of the amplifier) via a Brownlee (Santa Clara, CA) Precision Amplifier and injected into the second PD neuron to effectively voltage clamp the second PD neuron to the same $V_{\text {hold }}$ with only one electrode. To demonstrate that both PD neurons can be voltage clamped to the same membrane potential without the need to impale each neuron with two electrodes, a series of control experiments ( $n=5$; data not shown) were performed in which the $\mathrm{PD}$ neurons (referred to as $\mathrm{PD}_{1}$ and $\mathrm{PD}_{2}$ for this section of Materials and Methods) were impaled with two electrodes each, $\mathrm{PD}_{1}$ was voltage clamped, and the current used to voltage clamp it was scaled up and injected into microelectrode 2 of $\mathrm{PD}_{2}$. This current was effective in clamping the membrane potential of $\mathrm{PD}_{2}$ (as monitored by microelectrode 1) to the same membrane potential as $\mathrm{PD}_{1}$. The postsynaptic LP and PY neurons were impaled with one electrode each, and the elicited graded IPSPs were recorded in current clamp. Only paired recordings of LP and PY were used in this manuscript.

The VD neuron is coupled to the pacemaker neurons via a mixed chemical-electrical synapse and is also connected to both the LP and PY neurons through chemical synapses (Eisen and Marder, 1982). The inhibitory chemical component of the AB to VD synapse dominates during the normal ongoing rhythm (Maynard and Selverston, 1975; Miller and Selverston, 1982b; Johnson et al., 1993), and so, during an AB/PD burst, the VD neuron is inhibited and does not release transmitter onto the LP and PY neurons. Therefore, during the voltage-clamp stimulation of the PD neurons, it is expected that the VD neuron is inhibited and its synapses to the LP and PY neurons are inactive. However, as a precautionary measure, the VD neuron was photoinactivated in all experiments to eliminate possible contamination of the AB/PD-induced IPSPs in the LP and PY neurons by the VD neuron. The complete photoinactivation procedure has been outlined by Miller and Selverston $(1979,1982 a)$ and Eisen and Marder (1984).

Various injection protocols were used to stimulate the pacemaker chemical synapses onto the LP and PY neurons. To study the synapses in a static context, single square $2 \mathrm{~s}$ depolarizing pulses of amplitudes ranging from 10 to $40 \mathrm{mV}$ were injected into the voltage-clamped PD neurons. To study the extent of depression and recovery, trains of five square pulses of fixed $500 \mathrm{~ms}$ duration and $40 \mathrm{mV}$ amplitude, with interpulse intervals (IPIs) ranging from 250 to $8000 \mathrm{~ms}$, were used. The effects of varying the frequency and shape of the presynaptic depolarizations were investigated using trains of two realistic PD waveforms, each with a drastically different duty cycle. Duty cycle was defined as the percentage of time, in each cycle, that the PD waveform was above its mean membrane potential. Realistic waveforms were built by recording the membrane potential oscillations of the $\mathrm{PD}$ neurons in normal saline during slow (1358 ms) and fast $(623 \mathrm{~ms})$ pyloric cycle periods and averaging them over several cycles. The resulting two unitary realistic waveforms, characterized according to their duty cycles (17 and 46\%) were then low-pass filtered (at $10 \mathrm{~Hz}$ ) to remove all action potentials and scaled to 
a fixed $40 \mathrm{mV}$ amplitude from trough-to-peak. The waveforms were then played back periodically into the voltage-clamped PD neurons with frequencies ranging from 0.5 to $4 \mathrm{~Hz}$ (cycle periods, $2000-250 \mathrm{~ms}$ ), obtained by scaling the waveforms in the time domain. A $10 \mathrm{~s}$ interval was used between all injections to allow the synapses to completely recover from any form of synaptic plasticity. The same two waveforms were used in all experiments to allow for averaging of the data across preparations.

Space-clamp issues. The two presynaptic PD neurons are anatomically identical, each a monopolar neuron with a large soma coupled to a relatively large primary neurite and numerous secondary and tertiary neurites (King, 1976a,b). Moreover, the PD neurons are functionally similar; they exhibit similar intrinsic properties and make and receive similar synapses (Miller and Selverston, 1982a; Eisen and Marder, 1984; Hooper, 1997a). The synaptic contacts are found on the secondary neurites of the presynaptic and postsynaptic neurons and ramify within the neuropil of the STG (King, 1976a,b). Although the PD neurons are believed to be fairly electrotonically compact (Hartline et al., 1993), when they are voltage clamped at the soma, they experience loss of voltage control at the synaptic sites (Rabbah et al., 2005). This space-clamp issue, however, is most significant when the presynaptic neurons are clamped using waveforms with sharp rise times, like square pulses, and are minimized with the use of realistic waveforms with a smooth shape, injected at relatively low frequencies. Moreover, during normal ongoing activity, the relative sizes of the individual IPSPs recorded in the postsynaptic neuron are comparable with the IPSPs elicited during simulated action potentials injected in the soma of the presynaptic neuron (Eisen and Marder, 1982), indicating that waveforms with the sharpest transitions were minimally attenuated by the structural configuration of the neurons.

The realistic waveforms were amplified to $40 \mathrm{mV}$ to compensate for the attenuation of the presynaptic signal from the injection site in the soma to the synaptic release sites at the tips of the fine neurites.

Activation of the artificial synapses. The LP and PY neurons maintain constant relative phase over a wide frequency range in vivo (Rezer and Moulins, 1983). To investigate the role of the pacemaker synapses on the relative activity phase of the LP and PY neurons, the biological AB/PD synapse was replaced with an artificial synapse, and the phases of LP and PY were recorded as the cycle period of the artificial synapse was varied. The LP and PY neurons were impaled with two electrodes each, one for current injection and one for recording membrane potentials, whereas the PD neuron was impaled with one electrode and monitored in current clamp. Cycle period and the PD, LP, and PY neuron burst times were measured in reference to the PD neuron burst onset (see Fig. 1A). The activity phase of each neuron was calculated as the time difference $(\Delta t)$ between the burst onset (or end) of that neuron and the onset of the PD neuron burst divided by the cycle period.

The biological synapses were then functionally removed from the network by the application of $5 \mu \mathrm{M}$ PTX [blocker of the glutamatergic AB, LP, and PY synapses (Marder and Paupardin-Tritsch, 1978)] and $1 \mathrm{~mm}$ TEA [blocker of the cholinergic PD and VD synapses (Marder and Eisen, 1984)]. Note that this low concentration of TEA is not sufficient to significantly block potassium currents in these neurons (Graubard and Hartline, 1991; Kloppenburg et al., 1999; Peck et al., 2001). This protocol effectively removes the LP and PY reciprocal synapses as well; hence, the LP and PY neurons were left connected via electrical coupling only (Mamiya et al., 2003). The dynamic-clamp technique was used to activate the artificial AB/PD synapses (Sharp et al., 1993; Manor and Nadim, 2001). We defined a set of differential equations to mimic the dynamics of the $\mathrm{AB}$ synapses (namely, short latency and rapid rise time) and of the PD synapses (namely, long latency and slow rise time) (Eisen and Marder, 1982; Rabbah et al., 2002). All parameters, including the reversal potentials and conductances of the synapses, were identical for both LP and PY neurons (see Results). We used a presynaptic pulse voltage signal to activate the artificial dynamic-clamp synapse. This voltage signal was activated for the same duration and period as the burst duration and period of the biological PD neuron in control conditions. The synaptic current $\left(I_{\text {syn }}\right)$ was then calculated through continuous readings of the LP and PY neuron membrane potentials and was injected, in real time, into both LP and PY neurons simultaneously. The equations used by dynamic clamp for calculation of $I_{\text {syn }}$ were as follows:

$$
\begin{aligned}
I_{\text {syn }} & =g_{\text {syn }} A \times(1+B) \times\left(V_{\text {post }}-E_{\text {syn }}\right) \\
\tau_{X} \frac{d X}{d t} & =X_{\infty}\left(V_{\text {pre }}\right)-X ; X=A, B \\
X_{\infty}(V) & =\frac{1}{1+\exp \left(\frac{V-V_{m X}}{k_{m X}}\right)}
\end{aligned}
$$

where $V_{\text {post }}$ is $V_{\mathrm{LP}}$ or $V_{\mathrm{PY}}$ recorded in real time, $g_{\text {syn }}$ is $5 \mathrm{nS}, E_{\text {syn }}$ is -80 $\mathrm{mV}, V_{m A}$ is $-40 \mathrm{mV}, k_{m A}$ is $-2 \mathrm{mV}, V_{m B}$ is $-40 \mathrm{mV}, k_{m B}$ is $2 \mathrm{mV}, \tau_{A}$ is $20 \mathrm{~ms}$, and $\tau_{B}$ is $100 \mathrm{~ms}$. These parameters were selected to obtain appropriate fits to recordings of IPSPs with multiple pulses (see Fig. $3 A$ ).

Cycle period and the PD, LP, and PY neuron burst durations and phases were measured in reference to the onset of the presynaptic voltage signal. $I_{\text {syn }}$ was also activated at different periods, ranging from $500 \mathrm{~ms}$ plus PD burst duration to 8000 ms plus PD burst duration. Within each preparation, at least 10 cycles of activity were analyzed.

Recording, analysis, and statistics. An NI PCI-6070-E board (National Instruments, Austin, TX) was used for data acquisition and for current injection with the data acquisition software Scope and Dynamic Clamp developed in the LabWindows/CVI software environment (National Instruments) on a Windows XP operating system (Microsoft, Seattle, WA). A Digidata 1332A board was used for simultaneous data acquisition with pClamp 9 software (Axon Instruments, Union City, CA). The acquired data were saved as individual binary files and were analyzed with the Readscope software. Scope, Readscope, and Dynamic Clamp are software developed in our laboratory and are available for download at http://stg.rutgers.edu/software/index.htm. Statistica (Statsoft, Tulsa, OK) and Origin (OriginLab, Natick, MA) software packages were used for statistical and graphical analysis. Reported statistical significance indicated that the achieved significance level $p$ was below the critical significance level $\alpha=0.05$. All error bars shown and error values reported denote SEM.

\section{Results}

The pacemaker ensemble of the pyloric circuit consists of the $\mathrm{AB}$ and two PD neurons that drive the pyloric rhythmic activity. These neurons exhibit synchronous membrane potential oscillations (Fig. $1 A$, top two traces; for simplicity, only one PD neuron is shown) that are time locked by their strong electrical coupling (Maynard, 1972; Maynard and Selverston, 1975; Eisen and Marder, 1982; Miller and Selverston, 1982b). Each cycle of the triphasic pyloric rhythm consists of a simultaneous burst of action potentials in the pacemaker neurons, followed with a short delay by a burst of action potentials in the single LP neuron and then by a burst in the six to eight PY neurons (Fig. 1A). During the normal ongoing pyloric rhythm, the pacemaker neurons produce a compound IPSP onto the follower LP and PY neurons (Fig. $1 B$ ). It has been proposed that the synaptic connectivity within the pyloric network (Fig. 1B), along with the intrinsic properties of the follower neurons, interact to determine the relative activity phases (PD-LP-PY) over a wide frequency range $(0.5-2.0 \mathrm{~Hz})$ of the pyloric rhythm (Hartline and Gassie, 1979; Selverston and Moulins, 1985; Miller, 1987; Marder and Bucher, 2001; Nusbaum and Beenhakker, 2002; Mamiya et al., 2003).

We examine the extent to which the relative activity phases of the follower LP and PY neurons are determined by the dynamics of the synaptic inputs these neurons receive from the pacemaker neurons. This study is composed of two sets of experiments. First, using simultaneous recordings, we compare the dynamics of the IPSPs that the LP and PY neurons receive from the pacemaker ensemble using various injection stimuli. In a separate set of ex- 
periments, we block the synapses from the pacemaker ensemble and replace its synaptic influence to the LP and PY neurons with artificial synapses using the dynamicclamp technique. These artificial pacemaker IPSPs mimic the biological IPSPs under control conditions but can be controlled in their strength and timing. Together, these experiments help determine the role synaptic dynamics play in producing the correct relative activity phase of the follower neurons in this rhythmic network.

\section{Comparison of the dynamics of the} IPSPs from the pacemaker unit onto the LP and PY neurons

Previous studies have shown the usefulness of single, long, square pulses in the study of graded synaptic transmission in the STNS (Maynard and Selverston, 1975; Graubard, 1978; Johnson and HarrisWarrick, 1990; Manor et al., 1997). Figure $2 A$ shows simultaneous responses of the LP (middle trace) and PY (bottom trace) neurons to a $2 \mathrm{~s}$ presynaptic square pulse in both PD neurons from -60 to $-20 \mathrm{mV}$ (top trace) in TTX saline. The follower neurons experienced the effect of synaptic release from the pacemaker ensemble as a whole because the $A B$ synapse is recruited from the PD neurons, thereby producing a compound IPSP (Rabbah et al., 2002). The $2 \mathrm{~s}$ depolarization pulse delivered to the PD neurons evoked a large transient peak hyperpolarization (Fig. $2 \mathrm{~A}$, horizontal arrows) that decayed to a sustained value throughout the stimulation period (Fig. $2 A$, vertical arrows) in both the LP and PY neurons. The strengths of the IPSPs elicited in response to all presynaptic depolarization amplitudes $\left(V_{\text {pre }}\right.$ from -60 to $-50,-40$, $-30,-20 \mathrm{mV})$ are shown in the input-output (I-O) curve in Figure $2 B$. As expected from a graded synapse, the IPSP amplitudes elicited in both the LP and PY neurons became larger with increasing presynaptic potentials. However, the amplitudes of the IPSPs from the pacemaker ensemble to the LP and PY neurons were not significantly different from each other (two-way ANOVA, $p=0.899 ; n=6$ ).

The IPSP amplitude provides a simple measure of synaptic strength but carries no information on synaptic dynamics. To examine the time course of synaptic transmission, the time-topeak $(\Delta t)$ of the IPSPs was quantified by calculating the time difference between the presynaptic pulse onset and the IPSP peak (Fig. $2 C$, inset) and plotting the values versus $V_{\text {pre }}$ (from -60 to $-50,-40,-30,-20 \mathrm{mV}$ ) (Fig. $2 C$ ). As the magnitude of presynaptic depolarization increased, the postsynaptic responses in the LP and PY neurons peaked earlier in time. However, the latency of the peak hyperpolarization of the pacemaker synapse to the LP neuron was not significantly different from that to the PY neuron (two-way ANOVA, $p=0.135 ; n=6$ ).
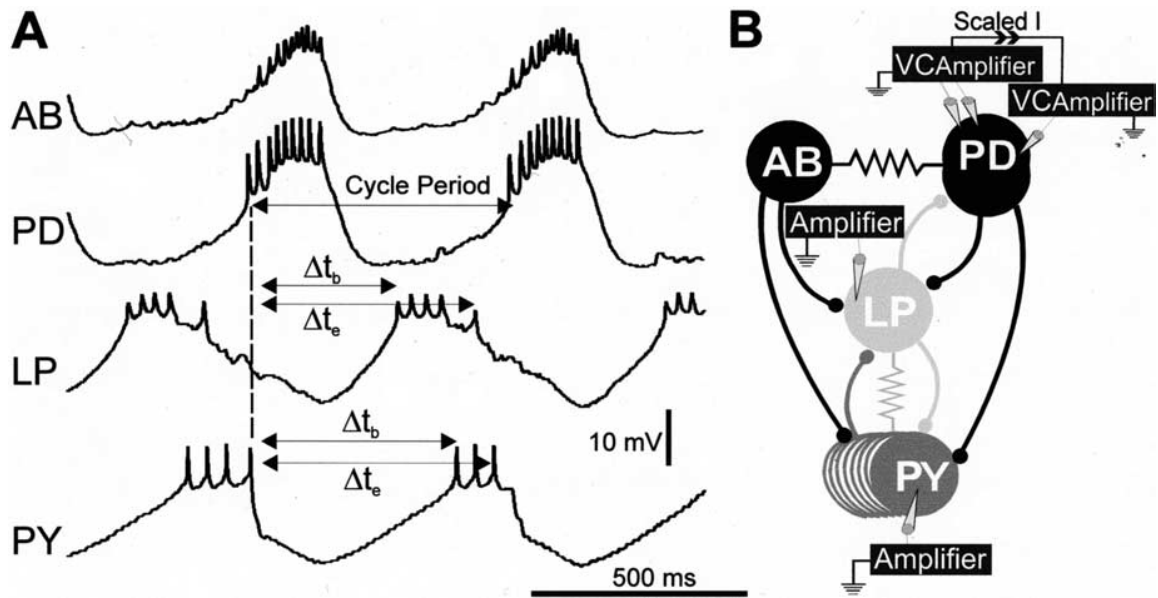

Figure 1. Pyloric network connectivity and experimental paradigm. $\boldsymbol{A}$, Intracellular recordings of $A B, P D, L P$, and PY in normal saline. The sequence of firing is such that the pacemaker neurons ( $A B$ and PD) burst in synchrony, followed, after a short delay, by PD burst onset as the reference point (dashed line). Phase is calculated by dividing the time difference between burst onset $\left(\Delta t_{\mathrm{b}}\right)$, or burst end $\left(\Delta t_{\mathrm{e}}\right)$, by cycle period. The baselines for the membrane oscillations were $-62 \mathrm{mV}$ for $\mathrm{AB},-57 \mathrm{mV}$ for PD, $-58 \mathrm{mV}$ setup. $A B$ and $P D$ are connected to $L P$ and PY by inhibitory chemical synapses. LP and PY are connected to each other with (electrical and chemical) synapses. All neurons were impaled with one electrode, except for one of the PD neurons injected into the other PD neuron to voltage clamp the latter to the same $V_{\text {hold }}$. Paired recordings of the LP and PY neurons were taken as the PD neurons were stimulated with various protocol injections. Resistor symbols denote electrical synapses; ball and
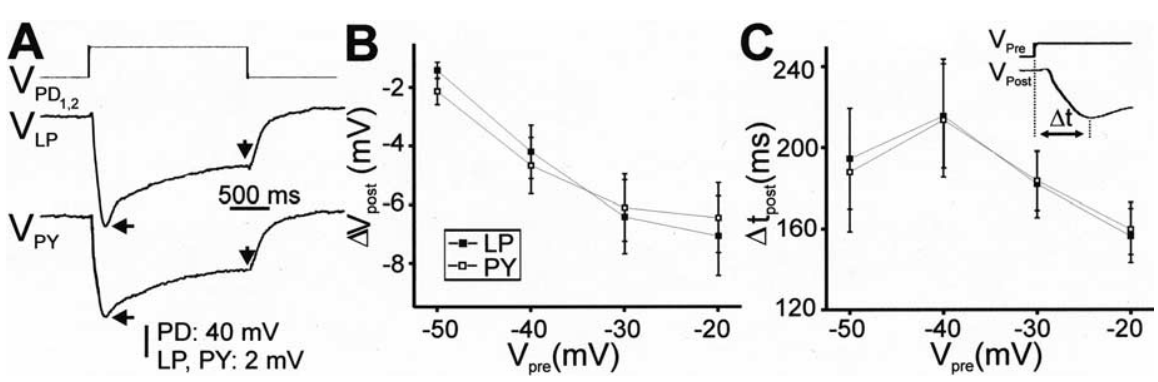

Figure 2. IPSPs elicited in the LP and PY neurons in response to single square voltage pulses in the PD neurons are similar in strength and time course. $A$, Simultaneous recording of $L P$ and $P Y$ as the $P D$ neurons were stimulated with a $40 \mathrm{mV}$ pulse from $V_{\text {hold }}$ of $-60 \mathrm{mV}$ in TTX saline. IPSPs exhibited a transient peak (horizontal arrows) and a sustained component (vertical arrows). The $\left(V_{\text {pre }}\right.$ from -60 to $-50,-40,-30,-20 \mathrm{mV}$ ) in the PD neurons (mean \pm SEM; $n=6$ ). Strengths of the IPSPs in LP and PY were similar time course of synaptic release (mean $\pm \mathrm{SEM} ; n=6$ ). Inset, Calculation of $\Delta t$ from the start of the presynaptic pulse to the peak of the hyperpolarization response.

All synapses in the pyloric network exhibit short-term synaptic dynamics (Hartline and Graubard, 1992; Manor et al., 1997; Mamiya et al., 2003; Mamiya and Nadim, 2004). To characterize the short-term dynamics of the synapses from the pacemaker ensemble to the LP and PY neurons, we activated the synapses with multiple square pulses (500 ms duration) of different interpulse intervals (IPI, 250-8000 ms) (Fig. 3). In response to a train of pulses with $500 \mathrm{~ms}$ IPI, the synapses onto both LP (middle trace) and PY (bottom trace) neurons showed short-term depression: the IPSPs elicited by the second and subsequent presynaptic depolarization pulses (Fig. $3 A$, vertical arrow) were smaller in amplitude than those elicited by the first pulse (Fig. $3 A$, horizontal arrow). Figure $3 B$ quantifies the extent of synaptic depression as the ratio of the fifth IPSP peak amplitude to the first plotted versus IPI (Manor et al., 1997; Mamiya et al., 2003). The LP and 


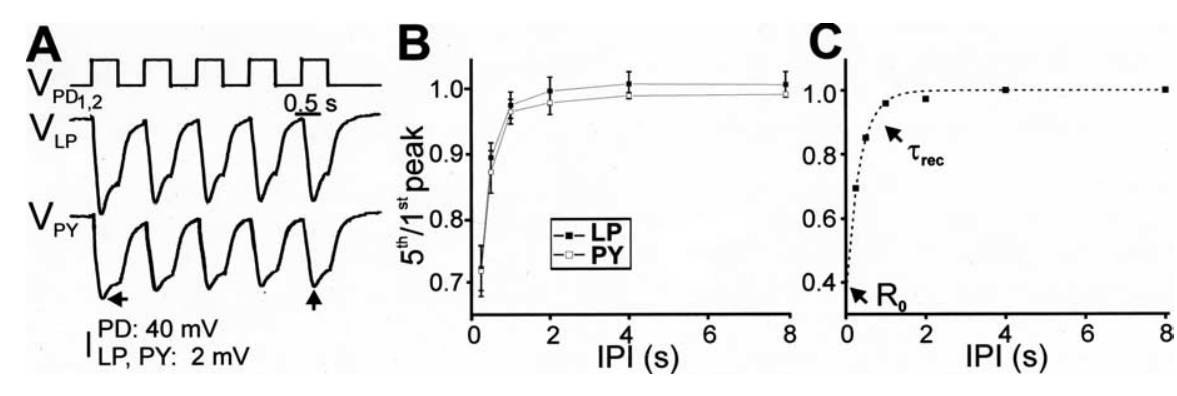

Figure 3. Short-term synaptic plasticity of the IPSPs elicited in the LP and PY neurons were similar in response to a train of pulses in the PD neurons. $A$, The PD neurons were stimulated with a series of five pulses of $40 \mathrm{mV}$ from $V_{\text {hold }}$ of $-60 \mathrm{mV}$ with an IPI of 500 ms. The IPSPs in LP and PY showed short-term depression: the steady-state IPSP (vertical arrow) is smaller in amplitude than the first IPSP (horizontal arrow). The resting membrane potentials were $-55 \mathrm{mV}$ for LP and $-56 \mathrm{mV}$ for PY. $\boldsymbol{B}_{\text {, }}$ The extent of depression of the IPSPS, measured as the ratio of the fifth/first peak amplitudes at each IPI, was similar for both LP and PY (mean \pm SEM; $n=6$ ). C, In each experiment, the fifth/first ratio versus IPI was fit with a single-exponential fit (dashed line) with time constant $\tau_{\text {rec }}$. The $y$-intercept $\left(R_{0}\right)$ represents the extent of recovery as IPI tends to 0 .

PY synapses showed the greatest depression (ratio, $\approx 0.76$ ) with the shortest IPI used, and the magnitude of depression decreased as the synapses were allowed greater time to recover between stimulations (ratio of 1 indicates maximum recovery). The extent of depression of the IPSPs onto LP and PY at all IPIs tested were not significantly different from each other (two-way ANOVA, $p=0.99 ; n=6)$.

The time constant of recovery from depression was computed by fitting the ratio of fifth to first IPSP peak amplitude versus IPI for each experiment with a first-order exponential decay curve with time constant $\tau_{\text {rec }}$ (Fig. 3C). The exponential fit is described by the equation $\left(1-D_{\max }\right) e^{-\mathrm{IPI} / \text { rrec }}$, where $D_{\max }$ is the maximum amount of depression for a given synapse (when IPI tends to 0 ). The $y$-intercept $R_{0}$ (Fig. 3C, arrow) represents the extent of recovery from depression as IPI tends to 0 (Mamiya et al., 2003). Average $\tau_{\text {rec }}$ values for the synaptic depression seen in the LP and PY neurons were $299 \pm 42.6$ and $318 \pm 61.7 \mathrm{~ms}$, respectively (paired $t$ test, $p=0.773 ; n=6$ ), indicating that the pacemaker synapses to the LP and PY neurons recovered from depression with similar time courses. The maximum depression $D_{\max }=1-$ $R_{0}$ of these synapses was also statistically similar $(0.626 \pm 0.0586$ for the LP neuron and $0.573 \pm 0.0411$ for the PY neuron; paired $t$ test, $p=0.518 ; n=6$ ).

The pyloric network produces an ongoing rhythmic activity. Thus, the synaptic dynamics that are more relevant in the ongoing rhythm are those that are measured after the transient changes are over and the peak response no longer changes in amplitude (Fig. 3A, compare fourth and fifth peaks). We refer to the IPSP in response to the fifth pulse as the steady-state IPSP. We measured the peak time $(\Delta t)$ of the steady-state IPSPs at all IPIs. The steady-state $\Delta t$ values in both LP and PY showed a dependence on the presynaptic IPI. As IPI increased, the value of $\Delta t$ decreased (from LP, $204.67 \pm 13.86 \mathrm{~ms}$ at $250 \mathrm{~ms}$ IPI, and PY, $203.567 \pm 11.94 \mathrm{~ms}$ at $250 \mathrm{~ms} \mathrm{IPI}$; to LP, $162.83 \pm 15.59 \mathrm{~ms}$ at $8000 \mathrm{~ms}$ IPI and PY, $165 \pm 15.03 \mathrm{~ms}$ at $8000 \mathrm{~ms}$ IPI). At all IPIs measured, however, the steady-state $\Delta t$ for both LP and PY IPSPs were not significantly different from each other (two-way ANOVA, $p=0.957 ; n=6$ ).

So far, we have shown that IPSPs recorded in the LP and PY neurons are affected by the amplitude and time between depolarizations of the presynaptic pacemaker neurons in similar ways. However, it has been shown that the amplitude and time course of PSPs are dependent on both the shape of the presynaptic depolarizations and their frequency (Olsen and Calabrese, 1996;
Manor et al., 1997; Simmons, 2002; Mamiya and Nadim, 2004). To examine the effect of presynaptic frequency and waveform shape on the synapses from the pacemaker ensemble to the LP and PY neurons, we voltage clamped the presynaptic neurons using two different prerecorded realistic waveforms. The activity waveforms of the pyloric pacemaker neurons are relatively stereotyped across preparations (Mamiya and Nadim, 2004). However, the $\mathrm{AB} / \mathrm{PD}$ waveforms change in shape if external current is injected into these neurons to change the pyloric period (Abbott et al., 1991) or in the presence of extrinsic neuromodulation (Marder and Hooper, 1985; Flamm and Harris-Warrick, 1986a,b; Marder, 1987; Harris-Warrick and Marder, 1991). Therefore, we constructed the realistic waveforms by recording several cycles of PD neuron activity during fast (623 ms) (Fig. 4A, left, top trace) and slow (1358 ms) (Fig. 4A, right, top trace) pyloric cycle period and then averaging and low-pass filtering these cycles (Fig. $4 A$, bottom traces) (see Materials and Methods). We indexed the change in waveform shape by the waveform duty cycle and chose two representative duty cycles (46 and $17 \%$ ) to stimulate the presynaptic neurons (see Materials and Methods).

The realistic waveforms were played back into the two voltage-clamped PD neurons from a baseline of $-60 \mathrm{mV}$ with a fixed $40 \mathrm{mV}$ trough-to-peak amplitude and with frequencies ranging from 0.5 to $4 \mathrm{~Hz}$ (cycle period, 2000-250 ms) while the postsynaptic responses from the LP and PY neurons were measured. Figure $4 B$ shows an example of the IPSPs in the LP (middle trace) and PY (bottom trace) neurons in response to a train of waveform stimulations corresponding to the duty cycle $46 \%$ and cycle period of $1 \mathrm{~s}$. As with trains of voltage pulses, the IPSPs showed short-term depression. Both sets of IPSPs recovered from depression as the cycle period was increased (lower frequency) (Fig. 4C). However, the steady-state IPSP amplitudes were statistically similar in both LP and PY neurons (two-way ANOVA, $p=$ $0.448 ; n=6)$. The synaptic transmission from the pacemaker ensemble in response to the realistic waveform stimulation occurred with a delay for both the LP and PY neurons: in each of the five cycles of the PD neuron waveform, release occurred after the presynaptic potential reached a threshold of more than $-30 \mathrm{mV}$. The peak phase of the steady-state PSP hyperpolarization was calculated as $\Delta t$ /period ( $\Delta t$ from the peak of the presynaptic waveform to the peak IPSP) and plotted versus frequency (Fig. $4 D$ ). We found that the peak phase of the IPSPs in the LP and PY neurons advanced as the PD waveform oscillations became longer (shorter frequency; from LP, $0.21 \pm 0.025$ and PY, $0.18 \pm$ 0.017 at frequency $4 \mathrm{~Hz}$; to $\mathrm{LP},-0.145 \pm 0.007$ and PY, $-0.139 \pm 0.009$ at frequency $0.5 \mathrm{~Hz}$ ). Peak phase changed signs from positive to negative at a frequency of $\sim 1.25 \mathrm{~Hz}$. The trend observed was statistically similar in both cells (two-way ANOVA, $p=0.634 ; n=6$ ). When the voltage-clamped PD neurons were stimulated with the realistic waveform with duty cycle $17 \%$, we again observed that the dynamics of the IPSPs elicited in the LP and PY neurons were not significantly different from each other (two-way ANOVA, $p=0.936$ for amplitudes and $p=0.175$ for peak phases; $n=6$; data not shown). 

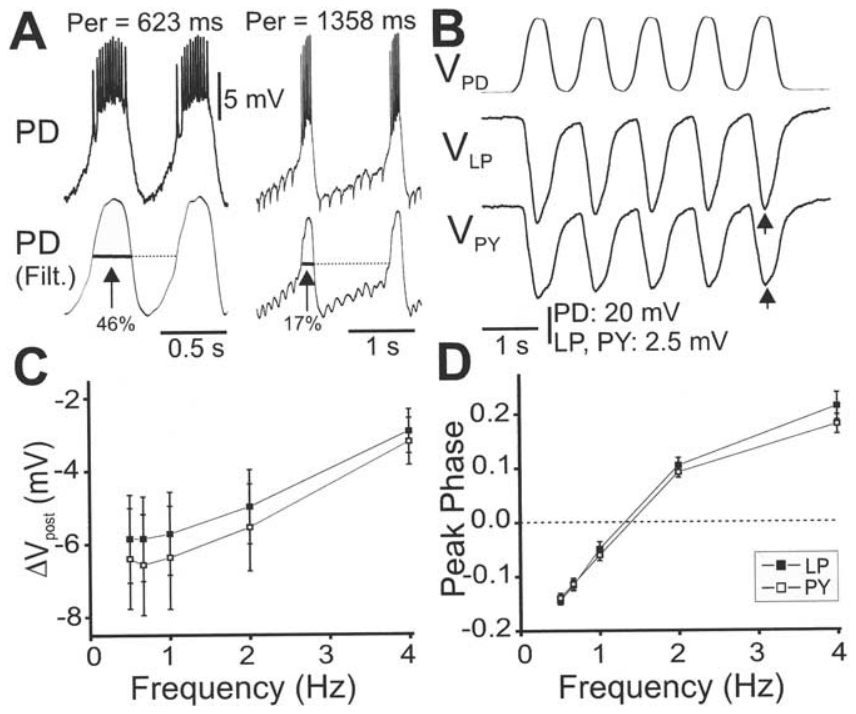

Figure 4. The frequency dependence of the IPSPs in the LP and PY neurons in response to a train of realistic waveforms in the PD neurons. $A$, Construction of realistic waveforms. Waveforms were recorded in the PD neuron (top traces) and low-pass filtered at $10 \mathrm{~Hz}$ to produce smooth unitary waveforms (bottom traces) at fast (left) and slow (right) cycle periods. The duty cycle (percentage of time above mean membrane potential) of the PD waveforms were 46 and $17 \%$. $\boldsymbol{B}$, A train of the realistic waveform in the left panel in $\boldsymbol{A}$ (scaled to $40 \mathrm{mV}$ amplitude) was played back into the voltage-clamped PD neurons from $V_{\text {hold }}$ of $-60 \mathrm{mV}$ (top trace) at cycle period $1 \mathrm{~s}$. The PSPs in LP and PY were recorded (middle and bottom traces, respectively) simultaneously. IPSPs in LP and PY exhibited short-term depression. The resting membrane potentials were $-55 \mathrm{mV}$ for LP and $-56 \mathrm{mV}$ for PY. Arrows indicate steady-state (fifth) IPSP peak amplitude. $\boldsymbol{C}$, The steady-state amplitude of the IPSPs (as indicated by arrows in $\boldsymbol{B}$ ) plotted versus frequency shows that the amplitudes of the synaptic response in LP and PY increased as the frequency decreased. This indicated recovery from short-term depression of the IPSPS as period was increased (lower frequency). IPSPs recorded from both LP and PY show a similar dependency on frequency. $D$, In response to increasing frequencies, the peak phase ( $\Delta t /$ period) of the steady-state IPSPs in LP and PY were delayed (mean \pm SEM; $n=6$ ). The response in the $L P$ and $P Y$ neurons showed a similar dependency on presynaptic frequency.

The relative activity phases of the follower LP and PY neurons are determined by their intrinsic properties and not by the synaptic inputs they receive from the pacemaker neurons Thus far, we have shown that the two intrinsically distinct follower LP and PY neurons in the pyloric network receive identical synaptic inputs from the pacemaker ensemble. These results suggested that the proper relative activity phase of the LP and PY neurons is not, as previously thought (Marder and Bucher, 2001; Nusbaum and Beenhakker, 2002; Mamiya et al., 2003), even partially determined by the synapses they receive from the $A B / P D$ pacemaker ensemble. To further validate this hypothesis, we removed the biological synapses from the pacemaker ensemble and drove the LP and PY neurons simultaneously with identical artificial synapses. If the LP and PY neurons maintain their relative phasing in the pyloric cycle because of their intrinsic properties, we expect that, when driven with identical synaptic inputs, the LP neuron should always lead the PY neuron in-phase within each cycle.

We first obtained simultaneous intracellular recordings of the PD, LP, and PY neurons in control conditions (Fig. 5A, top). These serve as our control recordings. The LP and PY neurons were impaled with two electrodes each, and the PD neuron was impaled with one electrode. The cycle period and phase of the neurons were measured in reference to the burst onset of the PD neuron (see Materials and Methods). The floating bars in the top panel of Figure $5 A$ represent the average phase of 10 cycles of PD,
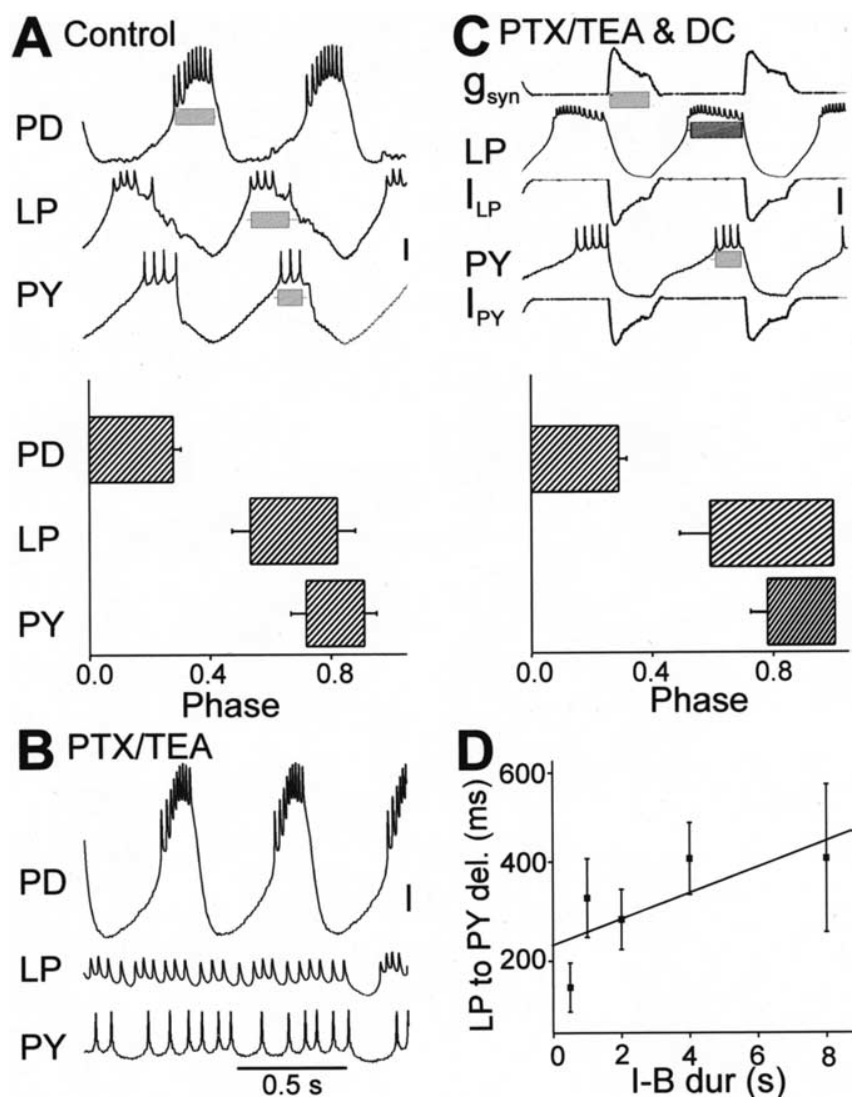

Figure 5. Synaptic transmission from the pacemaker neurons is not essential for proper phase of $L P$ and PY neuron activity. Calibration: $\boldsymbol{A}, \boldsymbol{B}, 5 \mathrm{mV} ; \boldsymbol{C}, 2.8 \mathrm{nS}, 1 \mathrm{nA}, 10 \mathrm{mV}$. $\boldsymbol{A}$, Simultaneous recordings of $P D, L P$, and $P Y$ in control saline. Floating bars in the top panel represent the average \pm SEM phase of activity $(n=10)$ for that preparation. The phase diagram in the bottom panel is the average of five preparations. The resting membrane potentials were -57 $\mathrm{mV}$ for PD, $-55 \mathrm{mV}$ for $L P$, and $-56 \mathrm{mV}$ for PY. $B$, Bath application of TEA and PTX removes the biological chemical synapses within the STG. Only PD maintained rhythmic oscillatory activity. The resting membrane potentials were $-55 \mathrm{mV}$ for $\mathrm{PD},-46 \mathrm{mV}$ for $\mathrm{LP}$, and $-44 \mathrm{mV}$ for $P Y$. C, While in PTX/TEA, artificial synapses that mimic the biological AB/PD synapses were activated for the same duration and period as that of the PD neuron in control conditions using the dynamic-clamp technique (DC). The synaptic conductance $\left(g_{\text {syn }} ;\right.$ top trace) as well as other parameters of $I_{\text {syn }}$ activated in the LP and PY neurons were identical. The value of $I_{\text {syn }}$ injected in the LP ( $I_{\mathrm{LP}}$; third trace) and PY ( $I_{P Y}$; last trace) neurons was calculated through continuous reading of the membrane potential of these neurons. In response to the artificial synaptic inputs, the LP and PY neurons maintained the correct relative phase of activity (floating bars). Phase was calculated using the presynaptic voltage signal as reference. Each of the first floating bars (in top and bottom panels) is meant to represent the phase of the artificial presynaptic voltage signal. As in $\boldsymbol{A}$, the phase diagram in the bottom panel represents the average of five preparations. The resting membrane potentials were $-46 \mathrm{mV}$ for $L P$ and $-44 \mathrm{mV}$ for PY. $D$, The time delay between the $L P$ and $P Y$ neuron burst onsets increased with the $I-B$ dur of $I_{\text {syn, }}$, but this increase was not statistically significant. The solid diagonal line shows the best linear fit of the data.

LP, and PY neuron activity measured in one experiment. The phase onsets of the LP and PY neurons in control recordings were $0.57 \pm 0.02$ and $0.78 \pm 0.1$, respectively ( $n=10$ cycles $)$. The average cycle period and burst duration of the PD neuron were $619 \pm 4.5$ and $193 \pm 1.5 \mathrm{~ms}$, respectively (mean $\pm \mathrm{SEM} ; n=10$ cycles). The phase diagram in the bottom panel of Figure $5 \mathrm{~A}$ shows the relative phase of the PD, LP, and PY neurons in control conditions $(n=5)$. In control conditions, the PD, LP, and PY neurons continued to maintain the proper firing sequence (PDLP-PY) as period was altered by external direct current injected in the PD neurons ( $n=4$; data not shown) (Hooper, 1997a). 
The biological synapses from the AB, LP, and PY neurons were then functionally removed from the network by bath application of the glutamatergic blocker PTX, whereas the cholinergic PD and VD synapses were blocked with $1 \mathrm{~mm}$ TEA (Fig. 5B). Together, these two compounds ensured that the LP and PY neurons were isolated from all chemical synaptic input within the STG. The cells, however, were still electrically coupled (Mamiya et al., 2003) and were still subject to neuromodulation from anterior ganglia (Marder, 1984, 1987; Harris-Warrick and Flamm, 1986; Marder and Weimann, 1992). In the PTX/TEA saline, the follower LP and PY neurons lost their ability to oscillate rhythmically (Fig. 5B, middle and bottom traces). However, the PD neuron, which is coupled to the endogenous oscillator neuron $\mathrm{AB}$, maintained its ability to oscillate but with a faster period ( $513.8 \pm 1.9 \mathrm{~ms} ; n=10$ cycles) than in control conditions (Fig. $5 B$, top trace). We then used an artificial "pacemaker" waveform to activate dynamic-clamp synaptic inputs into both the LP and PY neurons simultaneously (Fig. 5C) (see Materials and Methods). The conductance and dynamics of the artificial synaptic current $I_{\text {syn }}$ were identical for both cells. $I_{\text {syn }}$ was activated for the same duration and period as the average burst duration (193 ms) and period (619 ms) of the PD neuron measured in control conditions (Fig. 5C, top panel, top trace). Note that the ongoing PD neuron recording in PTX/TEA was not used as the presynaptic input. Instead a square-pulse waveform was used as the presynaptic voltage so that the period and active durations of the artificial synapse could be matched to the average values recorded in control conditions (see Materials and Methods).

Calculation of the phase (average of 10 cycles) using the onset of the artificial pacemaker waveform as the reference point showed that the LP and PY neurons maintained their relative phase of activity in each cycle (i.e., the LP neuron always fired before the PY neuron). This was true for every cycle of every experiment. The phase onsets were $0.62 \pm 0.01$ for the LP neuron and $0.74 \pm 0.02$ for the PY neuron in this preparation $(n=10$ cycles). The bottom panel in Figure $5 C$ shows the average phase diagram for five preparations. Note that the burst end phase for both the LP and PY neurons was 1.0 because these neurons fired tonically if they did not receive synaptic input; hence, their bursts were terminated by the next activation of the artificial $I_{\text {syn }}$. As expected, the average phase onsets of the LP and PY neurons were significantly different relative to each other in both response to the biological synapse and the artificial synapse (two-way ANOVA, $p=0.016 ; n=5$ ). However, the phase onsets of either the LP or the PY neuron in response to the artificial AB/PD synapse was not significantly different from the values in response to the biological AB/PD synapse (two-way ANOVA, post hoc analysis with Tukey's test, $p=0.589$ for LP and $p=0.538$ for PY; $n=5$ ).

One of the observations in the pyloric network activity is that the relative activity phase of the LP and PY neurons remains constant, despite large changes in cycle frequency (Hooper, $1997 b)$. To test this hypothesis, we activated $I_{\text {syn }}$ at different periods (see Materials and Methods) and examined whether this manipulation affects the time delay between the LP and PY neuron burst onsets. Because of the fact that the $I_{\text {syn }}$ period was calculated as a fixed PD burst duration plus an "interburst" time interval (see Materials and Methods), we examined the correlation between this time interval (I-B dur) and the LP to PY neuron time delay (Fig. 5D). The LP to PY burst onset delay increased slightly, but not significantly, across the range of I-B dur tested $(y=0.026 x+253 ; r=0.745 ; p=0.15 ; n=5)$.

\section{Discussion}

To produce meaningful rhythmic motor behaviors, neural networks must ensure proper coordination of the motor neurons involved in that behavior. Specifically, member neurons must be able to precisely adjust their relative timing of activity to maintain a functional motor pattern. Changing the timing relationship between neurons provides an oscillatory network with a way to switch from one functional output to another. For example, a switch from trotting to galloping in quadruped locomotion is obtained by changing the relative phases of the leg movements in each gait. Conversely, in fast or slow trotting or galloping, the relative phases of the legs remain mostly constant (Grillner, 1981).

Synaptic inputs have been proposed to be partially responsible for the activity patterns of neurons during motor behaviors such as walking in insects (Wolf, 1992; Tryba and Ritzmann, 2000) and the digestive process in crustaceans (Eisen and Marder, 1984). In the crustacean pyloric network in particular, the timing of the burst in the PY neuron was shown to be dependent on synaptic input from the pacemaker $\mathrm{PD}$ neuron and not the $\mathrm{AB}$ neuron (Eisen and Marder, 1984). Thus, it was suggested that synaptic connections set the proper activity phase of network neurons. We examined the role of synaptic inputs in maintaining proper phase relationships between two classes of follower neurons, LP and PY, in the pyloric network. The LP and PY neurons maintain a relative activity pattern in each cycle, with the LP neuron leading the PY neuron. This relative activity pattern has been partially attributed to the properties of the inhibitory synapses these neurons receive from the pacemaker ensemble (Nadim and Manor, 2000; Mamiya et al., 2003). To compare these synapses, we measured several characteristic parameters. A comparison of the strengths and time courses of the pacemaker synapses to the LP and PY neurons showed that these parameters are statistically similar, indicating that these neurons are inhibited by the pacemaker ensemble to the same degree and at precisely the same time. Moreover, both sets of synapses showed similar extent and time course of recovery from short-term depression, thereby ruling out the possibility that the relative activity phase of these neurons is determined by distinct synaptic dynamics (Manor et al., 2003). Neuromodulatory inputs from higher ganglia can alter the shape of the membrane potential waveforms of the pyloric neurons and the frequency of the rhythm (Flamm and Harris-Warrick, 1986a; Harris-Warrick and Marder, 1991). Such changes can result in variations of the synaptic outputs from the neurons (Manor et al., 1997; Mamiya et al., 2003). However, the strength and peak phase of the synapses to the LP and PY neurons showed the same dependency on the duty cycle and frequency of the PD neuron waveform. In summary, the comparison of all PSP parameters indicated that the synapses from the pacemaker ensemble to the LP and PY neurons are not significantly different.

\section{Pacemaker synapses are important in determining the activity} phase of the follower neurons but not their relative phase

We have provided strong evidence that synaptic inputs from the pacemaker ensemble do not dictate the relative activity phase of the LP and PY neurons. We emphasize that we do not claim that the absolute activity phase of these neurons (in reference to the activity of the pacemaker neurons) is independent of the synaptic inputs or insensitive to the synaptic dynamics. In fact, the synaptic connections from the pacemaker ensemble are clearly necessary for the oscillatory activity of the LP and PY neurons (Fig. 5B) (Miller and Selverston, 1982a,b). Moreover, the activity phase of each of these neurons is sensitive to the synaptic inputs they 
receive, as can be seen, e.g., by injecting artificial synaptic inputs (as in Fig. 5D) with different frequencies. The importance of the pacemaker synapses in determining the activity of the follower neurons was shown in early studies of these synapses (Eisen and Marder, 1982). Furthermore, the strength and short-term dynamics of the synaptic inputs are important parameters in determining the activity phase in each cycle (Manor et al., 2003; Bose et al., 2004; Greenberg and Manor, 2005). However, what we have shown in the current study is that the timing of activity of the LP and PY neurons relative to each other does not depend on the strength or dynamics of the synaptic inputs from the pacemaker ensemble but solely on the intrinsic properties of these follower neurons.

Previous studies have suggested that the relative phase of activity between LP and PY neurons is maintained relatively well across a range of frequencies, when frequency is altered by current injection in the pacemaker neurons (Hooper, 1997b). However, the phase-frequency relationship measured in individual preparations is subject to considerable variability across preparations (Bucher et al., 2005). Although our initial results indicate that there is an increase in the time delay between the burst onsets of these two neurons when frequency is altered, this increase is not statistically significant (Fig. 5D). Moreover, in this manipulation, we changed the (artificial) PD interburst interval and the synaptic input in each cycle was kept constant. A comprehensive examination of the influence of intrinsic versus synaptic properties on the relationship between phase and frequency would require a number of additional experimental manipulations that are beyond the scope of the current study.

\section{Intrinsic ionic currents can determine the relative activity phases of the LP and PY neurons}

Intrinsic membrane properties of neurons have been shown to play a role in the setting of relative phase in various motor systems. For example, spike-frequency adaptation affects the activity pattern of neurons involved in lamprey locomotion (el Manira et al., 1994) and rat respiration (Jodkowski et al., 1988), whereas plateau potentials affect relative phasing in insect locomotion (Hancox and Pitman, 1991) and flight (Ramirez and Pearson, 1991). In the pyloric network, two subthreshold ionic conductances participate in the postinhibitory rebound property of the follower neurons: the fast transient potassium current $I_{\mathrm{A}}$ (Hartline, 1979; Hartline and Gassie, 1979; Tierney and HarrisWarrick, 1992; Harris-Warrick et al., 1995a,b) and the hyperpolarization-activated inward current $I_{\mathrm{h}}$ (Hartline and Gassie, 1979; Golowasch et al., 1992; Kiehn and Harris-Warrick, 1992; LoFaro et al., 1994). $I_{\mathrm{A}}$ delays the burst onset, whereas $I_{\mathrm{h}}$ advances it (Tierney and Harris-Warrick, 1992; Harris-Warrick et al., 1995b). The properties of these ionic conductances are different in the LP and PY neurons. Specifically, $I_{\mathrm{A}}$ is larger in the PY neuron and smaller in the LP neuron (Harris-Warrick, 1989; Tierney and Harris-Warrick, 1992), whereas $I_{\mathrm{h}}$ is almost nondetectable in the PY neuron but prominent in the LP neuron (Harris-Warrick et al., 1995a,b). These differences can account for the setting of relative phase of activity of these two neurons in the ongoing pyloric rhythm. In particular, when the pacemaker neurons burst, the LP and PY neurons experience inhibitory chemical PSPs with similar strengths and dynamics. The additional $I_{\mathrm{h}}$ then allows the LP neuron to escape from inhibition first, whereas the additional $I_{\mathrm{A}}$ delays the onset of the PY burst. In this manner, these two intrinsic ionic conductances can set the relative phasing of activity in the LP and PY neurons.

\section{Synapses from the same neuron can have distinct strengths and dynamics}

We show that two synapses efferent from one presynaptic neuronal unit have identical dynamics. Although this is true for the case presented here, it is not true in general, even for synapses in the pyloric network. A recent study (Mamiya and Nadim, 2005) shows that the synaptic connections from the LP neuron to the PD and PY neurons have vastly different strengths and shortterm dynamics. In addition, the short-term dynamics of these synapses are customized for their specific functions, suggesting that heterogeneity in synaptic dynamics allows the presynaptic neuron to differentially control the activity of its postsynaptic targets.

\section{Neuromodulation may change the effect of pacemaker synapses on the relative activities of the LP and PY neurons}

In this study, we treated the pacemaker neurons $\mathrm{AB}$ and $\mathrm{PD}$ as one unit because, in the ongoing pyloric rhythm, these neurons are always coactive and both make synaptic connections to the follower LP and PY neurons. However, the synapses from the AB and PD neurons differ in their neurotransmitter content, time course (Marder and Eisen, 1984; Rabbah et al., 2002), and shortterm dynamics (our unpublished observations) (Rabbah et al., 2002). Previous studies have shown that neuromodulators released from higher ganglia to the pyloric network differentially affect the intrinsic and synaptic properties of the pacemaker neurons (Johnson et al., 1995; Harris-Warrick et al., 1998). In this manner, neuromodulatory conditions can modify the relative contributions of the $\mathrm{AB}$ and $\mathrm{PD}$ synapses to the total synaptic output of the pacemaker ensemble. It is possible that, under some modulatory conditions, the pacemaker synapses to the LP and PY neurons can be modified to have distinct strengths or dynamics and thus directly influence the relative activity phase of these follower neurons.

\section{Conclusion}

The hypothesis that synaptic inputs interact with the intrinsic properties of individual neurons to maintain relative activity patterns may be valid in many oscillatory networks (Katz and Frost, 1996; Ramirez and Richter, 1996; Nassel, 2000; Clemens and Katz, 2001), despite our results that synaptic inputs from pacemaker neurons do not determine the relative activity of the follower neurons in the lobster pyloric circuit. The important lesson of the current study is to question the a priori assumption that distinct synaptic inputs are necessary for producing distinct postsynaptic activity patterns (Harris-Warrick et al., 1995a; Marder and Bucher, 2001; Mamiya et al., 2003). A complete analysis of the properties of all constituent neurons and synapses operating within a network, and their interactions with each other, is necessary to determine the mechanisms underlying the proper activity patterns of neurons and their relative coordination.

\section{References}

Abbott LF, Marder E, Hooper SL (1991) Oscillating networks: control of burst duration by electrically coupled neurons. Neural Comput 3:487497.

Bose A, Manor Y, Nadim F (2004) The activity phase of postsynaptic neurons in a simplified rhythmic network. J Comput Neurosci 17:245-261.

Bucher D, Prinz AA, Marder E (2005) Animal-to-animal variability in motor pattern production in adults and during growth. J Neurosci 25:1611-1619.

Clemens S, Katz PS (2001) Identified serotonergic neurons in the Tritonia 
swim CPG activate both ionotropic and metabotropic receptors. J Neurophysiol 85:476-479.

Dicaprio R, Jordan G, Hampton T (1997) Maintenance of motor pattern phase relationships in the ventilatory system of the crab. J Exp Biol 200:963-974.

Eisen JS, Marder E (1982) Mechanisms underlying pattern generation in lobster stomatogastric ganglion as determined by selective inactivation of identified neurons. III. Synaptic connections of electrically coupled pyloric neurons. J Neurophysiol 48:1392-1415.

Eisen JS, Marder E (1984) A mechanism for production of phase shifts in a pattern generator. J Neurophysiol 51:1375-1393.

el Manira A, Tegner J, Grillner S (1994) Calcium-dependent potassium channels play a critical role for burst termination in the locomotor network in lamprey. J Neurophysiol 72:1852-1861.

Flamm RE, Harris-Warrick RM (1986a) Aminergic modulation in lobster stomatogastric ganglion. I. Effects on motor pattern and activity of neurons within the pyloric circuit. J Neurophysiol 55:847-865.

Flamm RE, Harris-Warrick RM (1986b) Aminergic modulation in lobster stomatogastric ganglion. II. Target neurons of dopamine, octopamine, and serotonin within the pyloric circuit. J Neurophysiol 55:866-881.

Golowasch J, Buchholtz F, Epstein IR, Marder E (1992) Contribution of individual ionic currents to activity of a model stomatogastric ganglion neuron. J Neurophysiol 67:341-349.

Graubard K (1978) Synaptic transmission without action potentials: inputoutput properties of a nonspiking presynaptic neuron. J Neurophysiol 41:1014-1025.

Graubard K, Hartline DK (1991) Voltage clamp analysis of intact stomatogastric neurons. Brain Res 557:241-254.

Graubard K, Raper JA, Hartline DK (1980) Graded synaptic transmission between spiking neurons. Proc Natl Acad Sci USA 77:3733-3735.

Greenberg I, Manor Y (2005) Synaptic depression in conjunction with a-current channels promote phase constancy in a rhythmic network. J Neurophysiol 93:656-677.

Grillner S (1981) Control of locomotion in bipeds, tetrapods and fish. In: Handbook of physiology. The nervous system. Motor control, pp 11791236. Baltimore: Waverly.

Hancox JC, Pitman RM (1991) Plateau potentials drive axonal impulse bursts in insect motoneurons. Proc R Soc Lond B Biol Sci 244:33-39.

Harris-Warrick RM (1989) Forskolin reduces a transient potassium current in lobster neurons by a cAMP-independent mechanism. Brain Res 489:59-66.

Harris-Warrick RM, Flamm RE (1986) Chemical modulation of a small central pattern generator circuit. Trends Neurosci 9:432-437.

Harris-Warrick RM, Marder E (1991) Modulation of neural networks for behavior. Annu Rev Neurosci 14:39-57.

Harris-Warrick RM, Nagy F, Nusbaum MP (1992) Neuromodulation of stomatogastric networks by identified neurons and transmitters. In: Dynamic biological networks: the stomatogastric nervous system (HarrisWarrick RM, Marder E, Selverston AI, Moulins M, eds), pp 87-138. Cambridge, MA: MIT.

Harris-Warrick RM, Coniglio LM, Barazangi N, Guckenheimer J, Gueron S (1995a) Dopamine modulation of transient potassium current evokes phase shifts in a central pattern generator network. J Neurosci 15:342-358.

Harris-Warrick RM, Coniglio LM, Levini RM, Gueron S, Guckenheimer J (1995b) Dopamine modulation of two subthreshold currents produces phase shifts in activity of an identified motoneuron. J Neurophysiol 74:1404-1420.

Harris-Warrick RM, Johnson BR, Peck JH, Kloppenburg P, Ayali A, Skarbinski J (1998) Distributed effects of dopamine modulation in the crustacean pyloric network. Ann NY Acad Sci 860:155-167.

Hartline DK (1979) Pattern generation in the lobster (Panulirus) stomatogastric ganglion. II. Pyloric network simulation. Biol Cybern 33:223-236.

Hartline DK, Gassie Jr DV (1979) Pattern generation in the lobster (Panulirus) stomatogastric ganglion. I. Pyloric neuron kinetics and synaptic interactions. Biol Cybern 33:209-222.

Hartline DK, Graubard K (1992) Cellular and synaptic properties in the crustacean stomatogastric nervous system. In: Dynamic biological networks: the stomatogastric nervous system (Harris-Warrick RM, Marder E, Selverston AI, Moulins M, eds), pp 31-86. Cambridge, MA: MIT.

Hartline DK, Gassie DV, Jones BR (1993) Effects of soma isolation on outward currents measured under voltage clamp in spiny lobster stomatogastric motor neurons. J Neurophysiol 69:2056-2071.

Hooper SL (1997a) Phase maintenance in the pyloric pattern of the lobster
(Panulirus interruptus) stomatogastric ganglion. J Comput Neurosci 4:191-205.

Hooper SL (1997b) The pyloric pattern of the lobster (Panulirus interruptus) stomatogastric ganglion comprises two phase-maintaining subsets. J Comput Neurosci 4:207-219.

Jodkowski JS, Viana F, Dick TE, Berger AJ (1988) Repetitive firing properties of phrenic motoneurons in the cat. J Neurophysiol 60:687-702.

Johnson BR, Harris-Warrick RM (1990) Aminergic modulation of graded synaptic transmission in the lobster stomatogastric ganglion. J Neurosci 10:2066-2076

Johnson BR, Peck JH, Harris-Warrick RM (1993) Amine modulation of electrical coupling in the pyloric network of the lobster stomatogastric ganglion. J Comp Physiol A Neuroethol Sens Neural Behav Physiol 172:715-732.

Johnson BR, Peck JH, Harris-Warrick RM (1995) Distributed amine modulation of graded chemical transmission in the pyloric network of the lobster stomatogastric ganglion. J Neurophysiol 74:437-452.

Katz PS, Frost WN (1996) Intrinsic neuromodulation: altering neuronal circuits from within. Trends Neurosci 19:54-61.

Kiehn O, Harris-Warrick RM (1992) 5-HT modulation of hyperpolarizationactivated inward current and calcium-dependent outward current in a crustacean motor neuron. J Neurophysiol 68:496-508.

King DG (1976a) Organization of crustacean neuropil. I. Patterns of synaptic connections in lobster stomatogastric ganglion. J Neurocytol 5:207-237.

King DG (1976b) Organization of crustacean neuropil. II. Distribution of synaptic contacts on identified motor neurons in lobster stomatogastric ganglion. J Neurocytol 5:239-266.

Klimesch W (1999) EEG alpha and theta oscillations reflect cognitive and memory performance: a review and analysis. Brain Res Brain Res Rev 29:169-195.

Kloppenburg P, Levini RM, Harris-Warrick RM (1999) Dopamine modulates two potassium currents and inhibits the intrinsic firing properties of an identified motor neuron in a central pattern generator network. J Neurophysiol 81:29-38.

Laurent G, Wehr M, Davidowitz H (1996) Temporal representations of odors in an olfactory network. J Neurosci 16:3837-3847.

LoFaro T, Kopell N, Marder E, Hooper SL (1994) Subharmonic coordination in networks of neurons with slow conductances. Neural Comp 6:69-84.

MacKay-Lyons M (2002) Central pattern generation of locomotion: a review of the evidence. Phys Ther 82:69-83.

Mamiya A, Nadim F (2004) Dynamic interaction of oscillatory neurons coupled with reciprocally inhibitory synapses acts to stabilize the rhythm period. J Neurosci 24:5140-5150.

Mamiya A, Nadim F (2005) Target-specific short-term dynamics are important for the function of synapses in an oscillatory neural network. J Neurophysiol 94:2590-2602.

Mamiya A, Manor Y, Nadim F (2003) Short-term dynamics of a mixed chemical and electrical synapse in a rhythmic network. J Neurosci 23:9557-9564.

Manor Y, Nadim F (2001) Synaptic depression mediates bistability in neuronal networks with recurrent inhibitory connectivity. J Neurosci 21:9460-9470.

Manor Y, Nadim F, Abbott LF, Marder E (1997) Temporal dynamics of graded synaptic transmission in the lobster stomatogastric ganglion. J Neurosci 17:5610-5621.

Manor Y, Bose A, Booth V, Nadim F (2003) Contribution of synaptic depression to phase maintenance in a model rhythmic network. J Neurophysiol 90:3513-3528.

Marder E (1984) Mechanisms underlying neurotransmitter modulation of neuronal circuit. Trends Neurosci 7:48-53.

Marder E (1987) Neurotransmitters and neuromodulators. In: The crustacean stomatogastric system (Selverston AI, Moulins M, eds), pp 263-300. Berlin: Springer.

Marder E (2000) Motor pattern generation. Curr Opin Neurobiol 10:691-698.

Marder E, Bucher D (2001) Central pattern generators and the control of rhythmic movements. Curr Biol 11:R986-R996.

Marder E, Calabrese RL (1996) Principles of rhythmic motor pattern generation. Physiol Rev 76:687-717.

Marder E, Eisen JS (1984) Transmitter identification of pyloric neurons: 
electrically coupled neurons use different transmitters. J Neurophysiol 51:1345-1361.

Marder E, Hooper SL (1985) Neurotransmitter modulation of the stomatogastric ganglion of decopod crustaceans. In: Model neural networks and behavior (Selverston A, ed), pp 319-337. New York: Plenum.

Marder E, Paupardin-Tritsch D (1978) The pharmacological properties of some crustacean neuronal acetylcholine, gamma-aminobutyric acid, and L-glutamate responses. J Physiol (Lond) 280:213-236.

Marder E, Weimann JM (1992) Modulatory control of multiple task processing in the stomatogastric nervous system. In: Neurobiology of motor programme selection (Kien J, McCrohan C, Winlow B, eds), pp 3-19. New York: Pergamon.

Maynard DM (1972) Simpler networks. Ann NY Acad Sci 193:59-72.

Maynard DM, Selverston AI (1975) Organization of the stomatogastric ganglion of the spiny lobster. IV. The pyloric system. J Comp Physiol 100:161-182.

Maynard DM, Walton KD (1975) Effects of maintained depolarization of presynaptic neurons on inhibitory transmission in lobster neuropil. J Comp Physiol 97:215-243.

Miller JP (1987) Pyloric mechanisms. In: The crustacean stomatogastric system (Selverston AI, Moulins M, eds), pp 109-136. Berlin: Springer.

Miller JP, Selverston A (1979) Rapid killing of single neurons by irradiation of intracellularly injected dye. Science 206:702-704.

Miller JP, Selverston AI (1982a) Mechanisms underlying pattern generation in lobster stomatogastric ganglion as determined by selective inactivation of identified neurons. II. Oscillatory properties of pyloric neurons. J Neurophysiol 48:1378-1391.

Miller JP, Selverston AI (1982b) Mechanisms underlying pattern generation in lobster stomatogastric ganglion as determined by selective inactivation of identified neurons. IV. Network properties of pyloric system. J Neurophysiol 48:1416-1432.

Nadim F, Manor Y (2000) The role of short-term synaptic dynamics in motor control. Curr Opin Neurobiol 10:683-690.

Nassel DR (2000) Functional roles of neuropeptides in the insect central nervous system. Naturwissenschaften 87:439-449.

Nusbaum MP, Beenhakker MP (2002) A small-systems approach to motor pattern generation. Nature 417:343-350.

O’Keefe J, Recce ML (1993) Phase relationship between hippocampal place units and the EEG theta rhythm. Hippocampus 3:317-330.

Olsen OH, Calabrese RL (1996) Activation of intrinsic and synaptic currents in leech heart interneurons by realistic waveforms. J Neurosci 16:4958-4970.
Pareti G, De Palma A (2004) Does the brain oscillate? The dispute on neuronal synchronization. Neurol Sci 25:41-47.

Peck JH, Nakanishi ST, Yaple R, Harris-Warrick RM (2001) Amine modulation of the transient potassium current in identified cells of the lobster stomatogastric ganglion. J Neurophysiol 86:2957-2965.

Rabbah P, Golowasch J, Nadim F (2005) Effect of electrical coupling on ionic current and synaptic potential measurements. J Neurophysiol 94:519-530.

Rabbah PM, Atamturktur S, Nadim F (2002) Distinct synaptic dynamics by pacemaker neurons of a rhythmic neural network. Soc Neurosci Abstr 28:752.5.

Ramirez JM, Pearson KG (1991) Octopamine induces bursting and plateau potentials in insect neurones. Brain Res 549:332-337.

Ramirez JM, Richter DW (1996) The neuronal mechanisms of respiratory rhythm generation. Curr Opin Neurobiol 6:817-825.

Raper JA (1979) Nonimpulse-mediated synaptic transmission during the generation of a cyclic motor program. Science 205:304-306.

Rezer E, Moulins M (1983) Expression of the crustacean pyloric pattern generator in the intact animal. J Comp Physiol 153:17-28.

Selverston AI, Moulins M (1985) Oscillatory neural networks. Annu Rev Physiol 47:29-48.

Selverston AI, Russell DF, Miller JP (1976) The stomatogastric nervous system: structure and function of a small neural network. Prog Neurobiol 7:215-290.

Sharp AA, O’Neil MB, Abbott LF, Marder E (1993) Dynamic clamp: computergenerated conductances in real neurons. J Neurophysiol 69:992-995.

Simmons PJ (2002) Presynaptic depolarization rate controls transmission at an invertebrate synapse. Neuron 35:749-758.

Singer W (1993) Synchronization of cortical activity and its putative role in information processing and learning. Annu Rev Physiol 55:349-374.

Stopfer M, Bhagavan S, Smith BH, Laurent G (1997) Impaired odour discrimination on desynchronization of odour-encoding neural assemblies. Nature 390:70-74.

Tierney AJ, Harris-Warrick RM (1992) Physiological role of the transient potassium current in the pyloric circuit of the lobster stomatogastric ganglion. J Neurophysiol 67:599-609.

Tryba AK, Ritzmann RE (2000) Multi-joint coordination during walking and foothold searching in the Blaberus cockroach. II. Extensor motor neuron pattern. J Neurophysiol 83:3337-3350.

Von Euler C (1983) On the origin and pattern control of breathing rhythmicity in mammals. Symp Soc Exp Biol 37:469-485.

Wolf H (1992) Reflex modulation in locusts walking on a treadwheelintracellular recordings from motoneurons. J Comp Physiol 170:443-462. 